\title{
Desempenho produtivo de nespereiras enxertadas em marmeleiro 'Portugal'
}

\author{
Rafael Pio(1), Fernando Antônio Campo Dall'Orto(2), Wilson Barbosa(3), Edvan Alves Chagas ${ }^{(2)}$, Mário Ojima ${ }^{(4)}$ \\ e Nelson Pires Feldberg(5)
}

\begin{abstract}
(1) Universidade Estadual do Oeste do Paraná, Rua Pernambuco, № 1.777, Caixa Postal 1008, Centro, CEP 85960-000 Marechal Cândido Rondon, PR. E-mail: rafaelpio@hotmail.com (2)Instituto Agronômico (IAC), Centro Avançado de Pesquisa Tecnológica do Agronegócio de Frutas, Av. Luiz Pereira dos Santos, no 1.500, Corrupira, CEP 13214-820 Jundiaí, SP. E-mail: echagas@iac.sp.gov.br, facampo@iac.sp.gov.br (3)IAC, Centro Experimental Central, Caixa Postal 28, CEP 13001-970 Campinas, SP. E-mail: wbarbosa@iac.sp.gov.br (4)|AC, Centro Experimental Central, Seção de Fruticultura de Clima Temperado. E-mail: mojima@iac.sp.gov.br (5)Agência Paulista de Tecnologia do Agronegócio (APTA), Pólo Regional de Desenvolvimento Tecnológico dos Agronegócio, Regional Sudoeste Paulista, Caixa Postal 62, CEP $18300-960$ Capão Bonito, SP. E-mail: npfeldberg@yahoo.com.br
\end{abstract}

Resumo - O objetivo deste trabalho foi comparar o desempenho produtivo de cinco seleções de nespereiras enxertadas em marmeleiro e na própria nespereira. Foram utilizadas cinco seleções de nespereira: IAC 966-23, IAC 265-66, IAC 1467-25, Mizauto (IAC 167-4) e Mizumo (IAC 1567-411), enxertadas em estacas enraizadas de marmeleiro 'Portugal' (distribuídas no campo no espaçamento $4 \times 2 \mathrm{~m}$, densidade de 1.250 plantas ha- ${ }^{-1}$ ) e em plântulas de nespereiras (em espaçamento $7 \times 4 \mathrm{~m}$, densidade de 357 plantas ha $^{-1}$ ). O experimento foi conduzido no Município de Monte Alegre do Sul, SP. Nos três anos após o plantio das mudas no campo, avaliou-se a produção (quilograma e número de frutos por planta), massa média dos frutos ( $\mathrm{g}$ ) e a produtividade $\left(\mathrm{Mg} \mathrm{ha}^{-1}\right)$. Calculou-se a média dos quatro anos consecutivos de produção. A seleção IAC 265-66 apresentou o melhor desempenho em portaenxertos de marmeleiro e da própria nespereira. Apesar da menor produção, não houve diferença na produtividade entre os porta-enxertos do marmeleiro e da própria nespereira. $\mathrm{O}$ emprego de porta-enxertos de marmeleiro para nespereiras é uma opção para reduzir o porte e, conseqüentemente, facilitar tratos culturais.

Termos para indexação: Cydonia oblonga, Eriobotrya japonica, qualidade de fruto.

\section{Yield performance of loquat trees grafted on quince cultivar Portugal}

\begin{abstract}
The objective of this work was to compare the performance of five loquat selections grafted on quince seedlings and on loquat seedlings. The following selections were assessed: IAC 966-23, IAC 265-66, IAC 1467-25, Mizauto (IAC 167-4) and Mizumo (IAC 1567-411). The selections were grafted in rooted cuttings of quince cultivar Portugal (planted at the field with an spacing of $4 \times 2 \mathrm{~m}$, corresponding to a density of 1,250 plants ha ${ }^{-1}$ ) and in loquat seedlings (planted at the field with an spacing of $7 \times 4 \mathrm{~m}$, corresponding to a density of 357 plants ha $^{-1}$ ). The experiments were carried in Monte Alegre do Sul, SP, Brazil. Production (kg and number of the fruits per plant), fruit average mass $(\mathrm{g})$ and productivity $\left(\mathrm{Mg} \mathrm{ha}^{-1}\right)$, along three years of plantation at the field, were evaluated. After the last harvest, the average of all harvests was calculated. The IAC 265-66 selection showed the best performance when grafted on quince and loquat rootstocks. Despite the lower production, there was no difference in productive between quince and loquat as rootstocks. The use of quince as rootstock is an option for loquat cultivation, mainly due to the plant size reduction and consequently, the easier cultural practices.
\end{abstract}

Index terms: Cydonia oblonga, Eriobotrya japonica, fruit quality.

\section{Introdução}

Nos últimos anos, tem-se notado aumento significativo no consumo mundial de nêsperas (Eriobotrya japonica Lindl.) e aumento das áreas de cultivo, principalmente nos países orientais, maiores produtores e consumidores da fruta (Pio et al., 2007b). As folhas dessa frutífera são muito apreciadas, por suas propriedades farmacoterapêutica, no tratamento de doenças de pele e da diabetes, no tratamento anti-inflamatório, analgésico e agente expectorante, no tratamento de bronquite crônica e úlceras (Ito et al., 2000; Taniguchia et al., 2002; Hamada et al., 2004). 
O cultivo de nêsperas pode ser uma alternativa para a diversificação das propriedades frutícolas, em razão da época de produção de seus frutos, entre os meses de julho e setembro, época de escassez de frutas nas unidades produtoras, à exceção dos frutos cítricos e abacates (Ojima et al., 1999). Além de ser alternativa para o mercado de fruta fresca, pode ser processada industrialmente na fabricação de doces, em razão, principalmente, da riqueza de pectina em seus frutos (Ojima et al., 1999; Melo \& Lima, 2003).

O Estado de São Paulo é o maior produtor nacional de nêsperas (com produção de 3,7 milhões de caixas de $5 \mathrm{~kg}$ por ano), com destaque para o Município de Mogi das Cruzes, responsável pela produção anual de 2 milhões de caixas de $5 \mathrm{~kg}$ (Pio et al., 2007b). A nespereira é encontrada em 27 municípios do Estado de São Paulo, constituindo-se na oitava frutífera de clima temperadosubtropical mais cultivada em terras paulistas. As principais cultivares são: Mizuho, Precoce de Itaquera (Fukuhara) e Precoce de Campinas (IAC 165-31) (Barbosa et al., 2003).

A produção de mudas de nespereira é normalmente feita com uso de mudas enxertadas em plântulas da própria nespereira, em razão da falta de um portaenxerto específico. Os porta-enxertos são produzidos por sementes, pois as nespereiras possuem baixa capacidade de enraizamento de suas estacas e apresentam índice não superior a 15\%, com a utilização de estacas herbáceas (Scaloppi Júnior et al., 2004; Silva \& Pereira, 2004). O grande entrave para se produzir os porta-enxertos através de sementes está correlacionado à variabilidade genética dos indivíduos e à menor capacidade de adaptação em locais com solo úmido, em razão da intolerância das nespereiras a ambientes com alta umidade do solo (Hartmann et al., 2002; Pio et al., 2007b).

Estudos preliminares sobre a compatibilidade da enxertia de cultivares de nespereiras em porta-enxertos de marmeleiro (Cydonia oblonga Mill. e Chaenomeles sinensis Koehne) foram realizados, em fase de viveiro e em campo. Nesses estudos, constatou-se boa porcentagem de pegamento e bom desenvolvimento dos enxertos, em espaçamento reduzidos (4x2 m) (Campo Dall'Orto et al., 1990; Gonçalves et al., 1996). A vantagem dessa combinação intergenérica de enxertia, nos moldes da pereira enxertada em marmeleiro, é a obtenção de nespereiras com características desejáveis de nanismo e que possam ser exploradas economicamente, sob espaçamentos reduzidos, mesmo em solos úmidos e menos arejados, contra-indicados, quando as raízes são da própria nespereira (Campo Dall'Orto et al., 1990; Gonçalves et al., 1996).

Este trabalho foi realizado com o objetivo de comparar o desempenho produtivo de cinco seleções de nespereiras enxertadas em nespereira e marmeleiro 'Portugal'.

\section{Material e Métodos}

O experimento foi realizado em área do Pólo Regional de Desenvolvimento Tecnológico dos Agronegócio, Regional Sudoeste Paulista, em Monte Alegre do Sul,

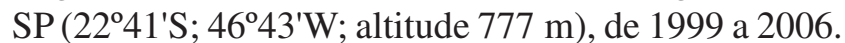
O clima da região, segundo classificação de Köppen, é mesotérmico de inverno seco (Cwa), comumente chamado de tropical de altitude, com temperatura anual média de $18^{\circ} \mathrm{C}$ e precipitação média anual de $1.300 \mathrm{~mm}$. O solo no local do experimento é raso, pouco desenvolvido e bem drenado, pertencente à classe Neossolo, fase substrato filito-xisto (Embrapa, 1999).

Foram extraídas sementes de frutos maduros da nespereira 'Mizuho', coletadas em julho de 1999, lavadas em água corrente e secadas à sombra por 48 horas. Posteriormente, foram semeadas em bandejas de plástico perfuradas $(30 \times 20 \mathrm{~cm})$, preenchidas com areia de grânulos médios e colocas em viveiro coberto com sombrite de náilon (50\% de luminosidade). Aos 90 dias após a semeadura, as plântulas foram transplantadas para sacos de plástico pretos (dimensões de $18 \times 30 \mathrm{~cm}$, capacidade de $3 \mathrm{~L}$ de substrato), preenchidos com substrato à base de casca de pínus, areia de grânulos médios e esterco de curral curtido $(1: 1: 1 \mathrm{v} / \mathrm{v})$ e mantidos nas mesmas condições de viveiro. Paralelamente, foram coletadas estacas lenhosas do marmeleiro 'Portugal', com $25 \mathrm{~cm}$ de comprimento e aproximadamente $10 \mathrm{~mm}$ de diâmetro, que foram colocadas para enraizar em sacos de plástico de igual tamanho e substrato similar, nas mesmas condições. Após o pleno enraizamento (60 dias após o estaqueamento), foi selecionada uma brotação e conduzida em haste única.

Em junho de 2000, quando os porta-enxertos apresentavam $70 \mathrm{~cm}$ de altura e diâmetro de $12 \mathrm{~mm}$ e as estacas $80 \mathrm{~cm}$ de altura e diâmetro de $15 \mathrm{~mm}$, em média, na altura de enxertia ( $15 \mathrm{~cm}$ acima do colo), foram enxertados pelo processo de garfagem em fenda cheia, a $15 \mathrm{~cm}$ de altura, pelo método inglês complicado. Foram utilizados garfos com três gemas, coletados das seguintes seleções de nespereira: IAC 966-23, IAC 265-66, 
IAC 1467-25, Mizauto (IAC 167-4) e Mizumo (IAC 1567-411). Os garfos enxertados foram protegidos com sacos de plástico transparentes e amarrados com barbante durante 30 dias para evitar a dessecação do material propagativo (Ojima et al., 1999).

Após cinco meses da enxertia, as mudas das seleções de nespereira enxertadas nas plântulas da nespereira 'Mizuho' foram plantadas em campo, sob espaçamento $7 \times 4 \mathrm{~m}$ (densidade de 357 plantas ha $^{-1}$ ), e as mudas de nespereiras enxertadas nas estacas enraizadas do marmeleiro 'Portugal' foram plantadas em campo, sob espaçamento 4x2 m (densidade de 1.250 plantas ha $^{-1}$ ). Foi utilizado o delineamento em blocos ao acaso, segundo o esquema fatorial $5 \times 2$, sendo o primeiro fator as seleções de nespereira e o segundo fator os porta-enxertos. Foram utilizados quatro blocos e cinco plantas por unidade experimental e consideradas para as análises apenas as três plantas centrais. As plantas foram adubadas anualmente, segundo análises de solo, e pulverizadas com fungicidas e inseticidas, quando necessário.

De 2003 a 2006, foram quantificadas a produção por planta e a massa média dos frutos frescos. A produtividade foi estimada na comparação entre os porta-enxertos. Os cachos foram desbastados e ensacados com papeljornal, mantendo-se apenas quatro frutos por cacho com diâmetro médio de 0,8 cm (Ojima et al., 1999). As colheitas foram realizadas entre os meses de junho e outubro, considerando-se os três picos anuais de maturação dos frutos. Nas variáveis analisadas, calcularam-se as médias do quadriênio.

Os dados foram submetidos à análise de variância e as médias ao teste de Tukey, a 5\% de probabilidade. As análises foram realizadas pelo SISVAR.

\section{Resultados e Discussão}

A produção média por planta das seleções de nespereira enxertadas sobre plântulas da própria nêspera, no primeiro ano de avaliação, foi superior na seleção IAC 265-66, com produção $72 \%$ maior que a nespereira 'Mizumo' e 27\% maior que a nespereira 'Mizauto' (Tabela 1). No segundo ano de produção, a superioridade da seleção IAC 265-66 foi mantida. No terceiro ano esta seleção não diferiu das nespereiras 'Mizumo' e 'Mizauto' (Tabela 1). Na última colheita, a seleção IAC 265-66 destacou-se novamente, culminando com maior produção média quadrienal (Tabela 1). Esses resultados implicam rápido retorno econômico ao fruticultor, o que minimiza gastos excessivos com a implantação.
Em pesquisa similar, realizada em Monte Alegre do Sul, SP, a nespereira 'Mizuho', uma das mais cultivadas em São Paulo (Barbosa et al., 2003), apresentou produção bem inferior no primeiro quadriênio (8,2 $\left.\mathrm{kg} \mathrm{planta}^{-1}\right)$ (Ojima et al., 1999), praticamente $11,02 \mathrm{~kg}$ planta $^{-1}$ a menos que a seleção IAC 265-66.

A seleção IAC 966-23 apresentou menor número de frutos por planta na safra de 2003, junto com a nespereira 'Mizumo', que também apresentou menor número de frutos por planta no biênio 2004-2005 (Tabela 1). No entanto, no quarto ano de produção, a seleção IAC 1467-25, que havia apresentado bons resultados no triênio anterior, produziu menor número de frutos por planta, o que influenciou a média do quadriênio 2003-2006, e se igualou às demais seleções que não diferiram estatisticamente entre si.

A seleção IAC 1467-25 produziu frutos com menor massa no quadriênio e na média das safras 2003-2006 (Tabela 1). A massa das frutas foi baixa nas diferentes seleções de nespereira (Tabela 1), o que consiste em fator limitante na comercialização das nêsperas, uma vez que o mercado exige frutas de maior tamanho (Martinez-Calvo et al., 1999; Agustí et al., 2000). Assim, a fim de aumentar o tamanho dos frutos das seleções

Tabela 1. Produção (peso e número de frutos por planta) e massa média dos frutos frescos de seleções de nespereiras (Eriobotrya japonica) enxertadas em plântulas de nespereira e plantadas no espaçamento de $7 \times 4 \mathrm{~m}$ e densidade de 357 plantas ha-1(1).

\begin{tabular}{lccccc}
\hline Seleções & 2003 & 2004 & 2005 & 2006 & Média \\
\hline & \multicolumn{5}{c}{ Produção (quilograma por planta) } \\
IAC 966-23 & $4,75 \mathrm{c}$ & $12,90 \mathrm{~b}$ & $17,85 \mathrm{~b}$ & $20,57 \mathrm{~b}$ & $14,02 \mathrm{~b}$ \\
IAC 265-66 & $8,22 \mathrm{a}$ & $18,57 \mathrm{a}$ & $22,25 \mathrm{a}$ & $27,95 \mathrm{a}$ & $19,22 \mathrm{a}$ \\
IAC 1467-25 & $5,42 \mathrm{c}$ & $12,27 \mathrm{~b}$ & $14,45 \mathrm{c}$ & $14,15 \mathrm{c}$ & $11,57 \mathrm{c}$ \\
Mizumo & $4,80 \mathrm{c}$ & $12,16 \mathrm{~b}$ & $20,43 \mathrm{a}$ & $26,01 \mathrm{a}$ & $15,85 \mathrm{~b}$ \\
Mizauto & $6,50 \mathrm{~b}$ & $13,23 \mathrm{~b}$ & $22,60 \mathrm{a}$ & $19,50 \mathrm{~b}$ & $15,46 \mathrm{~b}$ \\
\hline CV (\%) & 18,76 & 15,17 & 22,50 & 14,11 & 13,39 \\
\hline & & Produção (frutos por planta) & \\
IAC 966-23 & $135,7 \mathrm{~b}$ & $510,7 \mathrm{a}$ & $755,5 \mathrm{a}$ & $643,2 \mathrm{~b}$ & $511,3 \mathrm{a}$ \\
IAC 265-66 & $234,5 \mathrm{a}$ & $528,5 \mathrm{a}$ & $845,2 \mathrm{a}$ & $838,5 \mathrm{a}$ & $611,7 \mathrm{a}$ \\
IAC 1467-25 & $234,7 \mathrm{a}$ & $528,7 \mathrm{a}$ & $737,2 \mathrm{a}$ & $560,0 \mathrm{c}$ & $515,2 \mathrm{a}$ \\
Mizumo & $150,3 \mathrm{~b}$ & $387,4 \mathrm{~b}$ & $699,7 \mathrm{~b}$ & $836,6 \mathrm{a}$ & $518,5 \mathrm{a}$ \\
Mizauto & $201,6 \mathrm{a}$ & $599,6 \mathrm{a}$ & $874,0 \mathrm{a}$ & $609,3 \mathrm{~b}$ & $571,1 \mathrm{a}$ \\
\hline CV (\%) & 20,04 & 13,83 & 17,54 & 12,77 & 11,29 \\
\hline & & Massa média dos frutos (g) & \\
IAC 966-23 & $36,5 \mathrm{a}$ & $25,1 \mathrm{~b}$ & $23,6 \mathrm{~b}$ & $32,3 \mathrm{a}$ & $29,4 \mathrm{a}$ \\
IAC 265-66 & $34,1 \mathrm{a}$ & $35,3 \mathrm{a}$ & $26,1 \mathrm{a}$ & $32,2 \mathrm{a}$ & $32,0 \mathrm{a}$ \\
IAC 1467-25 & $23,2 \mathrm{~b}$ & $23,2 \mathrm{~b}$ & $19,6 \mathrm{c}$ & $25,9 \mathrm{~b}$ & $23,0 \mathrm{~b}$ \\
Mizumo & $32,0 \mathrm{a}$ & $31,4 \mathrm{a}$ & $29,2 \mathrm{a}$ & $31,1 \mathrm{a}$ & $30,9 \mathrm{a}$ \\
Mizauto & $33,7 \mathrm{a}$ & $22,0 \mathrm{~b}$ & $25,8 \mathrm{a}$ & $32,1 \mathrm{a}$ & $28,4 \mathrm{a}$ \\
\hline CV (\%) & 14,02 & 9,90 & 8,46 & 7,03 & 6,58 \\
\hline
\end{tabular}

(1)Médias seguidas pela mesma letra, na coluna, não diferem entre si pelo teste de Tukey, a $5 \%$ de probabilidade. 
de nespereira em questão, devem ser testadas técnicas alternativas, a exemplo da aplicação de 2,4-D (Agustí et al., 2003).

Nas seleções de nespereira enxertadas em marmeleiro, foram obtidas boas produções por planta na primeira safra para a seleção IAC 265-66 e para as nespereiras 'Mizumo' e 'Mizauto' (Tabela 2). No triênio 2004-2006, a seleção IAC 265-66 continuou em destaque e atingiu produção de $8,5 \mathrm{~kg}$ planta $^{-1}$ na última safra avaliada, com média no quadriênio de $5,43 \mathrm{~kg} \mathrm{planta}^{-1}$ (Tabela 2). Quanto ao número de frutos por planta, as seleções diferiram durante o quadriênio, porém não houve diferença estatística na média desse período (Tabela 2). Na última avaliação, a nespereira 'Mizauto' alcançou 312 frutos planta ${ }^{-1}$, o que corresponde a 390.000 frutos ha-1 (1.250 plantas ha-1). A seleção IAC 265-66 e a nespereira 'Mizumo' produziram frutos de maiores massas no biênio 2003-2004, com destaque para a seleção IAC 265-66 (Tabela 2).

A seleção IAC 265-66 enxertada sobre plântulas de nespereira apresentou a maior média de produção do quadriênio 2003-2006, de 19,22 kg planta-1 que, em

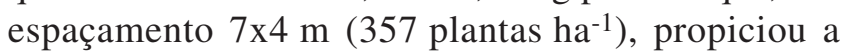
produtividade média de $6,86 \mathrm{Mg} \mathrm{ha}^{-1}$, contra 5,65 $\mathrm{Mg} \mathrm{ha}^{-1}$

Tabela 2. Produção (peso e número de frutos por planta) e massa média dos frutos frescos de seleções de nespereiras (Eriobotrya japonica) enxertadas em estacas enraizadas de marmeleiro 'Portugal' e plantadas no espaçamento de 4x2 m e densidade de 1.250 plantas $\mathrm{ha}^{-1(1)}$.

\begin{tabular}{lccccc}
\hline Seleções & 2003 & 2004 & 2005 & 2006 & Média \\
\hline & \multicolumn{5}{c}{ Produção (quilograma por planta) } \\
IAC 966-23 & $1,32 \mathrm{~b}$ & $2,73 \mathrm{ab}$ & $2,78 \mathrm{c}$ & $4,64 \mathrm{c}$ & $2,87 \mathrm{c}$ \\
IAC 265-66 & $2,58 \mathrm{a}$ & $3,07 \mathrm{a}$ & $7,57 \mathrm{a}$ & $8,50 \mathrm{a}$ & $5,43 \mathrm{a}$ \\
IAC 1467-25 & $1,26 \mathrm{~b}$ & $1,95 \mathrm{~b}$ & $5,75 \mathrm{~b}$ & $4,58 \mathrm{c}$ & $3,39 \mathrm{~b}$ \\
Mizumo & $2,55 \mathrm{a}$ & $2,23 \mathrm{~b}$ & $5,07 \mathrm{~b}$ & $6,93 \mathrm{~b}$ & $3,98 \mathrm{~b}$ \\
Mizauto & $2,88 \mathrm{a}$ & $2,25 \mathrm{~b}$ & $3,96 \mathrm{c}$ & $7,70 \mathrm{a}$ & $4,20 \mathrm{~b}$ \\
\hline CV (\%) & 28,47 & 31,00 & 11,88 & 21,14 & 18,40 \\
\hline & & Produção (frutos por planta) & \\
IAC 966-23 & $51,0 \mathrm{~b}$ & $104,2 \mathrm{a}$ & $143,2 \mathrm{c}$ & $192,5 \mathrm{c}$ & $122,8 \mathrm{a}$ \\
IAC 265-66 & $83,0 \mathrm{a}$ & $78,5 \mathrm{~b}$ & $229,0 \mathrm{~b}$ & $250,7 \mathrm{~b}$ & $160,3 \mathrm{a}$ \\
IAC 1467-25 & $48,5 \mathrm{~b}$ & $70,2 \mathrm{~b}$ & $307,0 \mathrm{a}$ & $174,0 \mathrm{c}$ & $149,9 \mathrm{a}$ \\
Mizumo & $79,2 \mathrm{a}$ & $68,2 \mathrm{~b}$ & $187,5 \mathrm{~b}$ & $214,7 \mathrm{~b}$ & $137,4 \mathrm{a}$ \\
Mizauto & $103,0 \mathrm{a}$ & $77,3 \mathrm{~b}$ & $182,3 \mathrm{~b}$ & $312,0 \mathrm{a}$ & $168,7 \mathrm{a}$ \\
\hline CV (\%) & 25,66 & 31,08 & 18,03 & 19,93 & 19,29 \\
\hline & & \multicolumn{5}{c}{ Massa média dos frutos $(\mathrm{g})$} & \\
IAC 966-23 & $25,7 \mathrm{~b}$ & $27,0 \mathrm{~b}$ & $19,8 \mathrm{~d}$ & $23,6 \mathrm{~d}$ & $24,0 \mathrm{c}$ \\
IAC 265-66 & $30,7 \mathrm{a}$ & $37,0 \mathrm{a}$ & $33,3 \mathrm{a}$ & $33,9 \mathrm{a}$ & $33,7 \mathrm{a}$ \\
IAC 1467-25 & $26,0 \mathrm{~b}$ & $27,4 \mathrm{~b}$ & $18,7 \mathrm{~d}$ & $26,4 \mathrm{c}$ & $24,6 \mathrm{c}$ \\
Mizumo & $32,1 \mathrm{a}$ & $32,9 \mathrm{a}$ & $27,0 \mathrm{~b}$ & $28,3 \mathrm{~b}$ & $30,1 \mathrm{~b}$ \\
Mizauto & $28,0 \mathrm{~b}$ & $29,3 \mathrm{~b}$ & $23,1 \mathrm{c}$ & $24,5 \mathrm{~d}$ & $26,2 \mathrm{c}$ \\
\hline CV (\%) & 6,61 & 11,04 & 7,52 & 3,07 & 4,67 \\
\hline
\end{tabular}

${ }^{(1)}$ Médias seguidas pela mesma letra, na coluna, não diferem entre si pelo teste de Tukey, a 5\% de probabilidade. da nespereira 'Mizumo' e 5,52 $\mathrm{Mg} \mathrm{ha}^{-1}$ da 'Mizauto' (Tabela 3). Em pesquisa similar, Ojima et al. (1999) obtiveram apenas $2,92 \mathrm{Mg} \mathrm{ha}^{-1} \mathrm{com}$ a nespereira 'Mizuho' em Monte Alegre do Sul, SP (22 $41^{\circ}$ 'S; $46^{\circ} 43^{\prime} \mathrm{W}$; altitude $777 \mathrm{~m}$ ). Porém, os resultados apresentados foram similares aos encontrados por Pio et al. (2007a), que registraram 5,29 $\mathrm{Mg} \mathrm{ha}^{-1}$ para a nespereira 'Mizuho', $5,57 \mathrm{Mg} \mathrm{ha}^{-1}$ para a 'Mizumo' e 5,64 $\mathrm{Mg} \mathrm{ha}^{-1}$ para a 'Mizauto', em Jundiaí, SP (238'S; 46 $55^{\circ} \mathrm{W}$; altitude $700 \mathrm{~m}$ ), região de condições climáticas similares. De acordo com Ojima et al. (1999), as nespereiras podem alcançar a produtividade média de $10 \mathrm{Mg} \mathrm{ha}^{-1}$, em plantas adultas com mais de oito anos de idade e adequadamente manejadas.

No caso das nespereiras enxertadas em marmeleiro, como as plantas apresentam porte reduzido, as produções por planta esperadas são menores, em relação às seleções enxertadas em plântulas da própria nespereira.

Na comparação do desempenho produtivo da seleção IAC 265-66 enxertada em plântulas de nespereira e estacas de marmeleiro 'Portugal' (Tabelas 1 e 2), na primeira colheita (safra de 2003), foi registrada produção de 8,22 $\mathrm{kg}_{\text {planta }}{ }^{-1}$ e produtividade de 2,93 $\mathrm{Mg} \mathrm{ha}^{-1} \mathrm{da}$ seleção enxertada em plântulas de nespereira. Para essa mesma seleção enxertada em marmeleiro, na safra de 2003, foi registrada a produção de $2,58 \mathrm{~kg}_{\text {planta-1 }} \mathrm{e}$ produtividade de $3,22 \mathrm{Mg} \mathrm{ha}^{-1}$. Pela média de produção do quadriênio 2003-2006, a seleção IAC 265-66 apresentou produtividade média de $6,86 \mathrm{Mg} \mathrm{ha}^{-1}$ para as plantas enxertadas em nespereira e $6,78 \mathrm{Mg} \mathrm{ha}^{-1}$ para as plantas enxertadas em marmeleiro.

Em geral, as médias de produtividade das cinco seleções de nespereiras em estudo propiciaram resultados superiores na primeira safra, nas plantas enxertadas em marmeleiro (2,60 Mg ha $\left.{ }^{-1}\right)$, em comparação com as

Tabela 3. Produtividade de seleções de nespereiras (Eriobotrya japonica) enxertadas em estacas enraizadas de marmeleiro 'Portugal' plantadas na densidade de 1.250 plantas ha ${ }^{-1}$ e em plântulas de nespereira plantadas na densidade de 357 plantas ha $^{-1(1)}$.

\begin{tabular}{lccccc}
\hline Porta-enxertos & 2003 & 2004 & 2005 & 2006 & Média \\
\hline \multirow{5}{*}{ Marmeleiro } & $2,60 \mathrm{a}$ & $3,07 \mathrm{~b}$ & $6,35 \mathrm{~ns}$ & $7,79 \mathrm{~ns}$ & $4,95 \mathrm{~ns}$ \\
Nespereira & $2,09 \mathrm{~b}$ & $4,91 \mathrm{a}$ & 6,93 & 7,82 & 5,44 \\
\hline CV $(\%)$ & 27,88 & 27,16 & 17,60 & 26,40 & 17,31 \\
\hline
\end{tabular}

${ }^{(1)}$ Médias seguidas pela mesma letra, na coluna, não diferem entre si pelo teste de Tukey, a 5\% de probabilidade. 
plantas enxertadas em nespereira $\left(2,09 \mathrm{Mg} \mathrm{ha}^{-1}\right)$ (Tabela 3). Na safra seguinte, o resultado foi inverso. Todavia, na média de produtividade do quadriênio 2003-2006, não houve diferença estatística entre ambos os porta-enxertos (Tabela 3 ).

A vantagem da utilização do marmeleiro como portaenxerto está na facilidade dos tratos culturais, principalmente quanto à aplicação de defensivos, poda, raleio e ensacamento dos frutos e também no maior aproveitamento das áreas de cultivo, em razão do espaçamento reduzido e, principalmente, no cultivo em solos úmidos e menos arejados, contra-indicados quando as raízes são da própria nespereira (Campo Dall'Orto et al., 1990; Ojima et al., 1999; Pio et al., 2007b). A maior desvantagem se verifica no maior custo de implantação, devido ao maior número de mudas utilizadas no plantio.

\section{Conclusões}

1. A seleção IAC 265-66 apresenta melhor desempenho produtivo sobre porta-enxertos de marmeleiro e da própria nespereira.

2. Não há diferença de produtividade de nespereira sobre porta-enxerto de marmeleiro e da própria nespereira.

3. O marmeleiro é uma excelente opção como portaenxertos para nespereiras, pois reduz o porte das plantas e facilita os tratos culturais.

\section{Referências}

AGUSTÍ, M.; GARIGLIO, N.; CASTILLO, A.; JUAN, M.; ALMELA, V.; MARTINEZ-FUENTES, A.; MESEJO, C. Effect of the synthetic auxin 2,4-DP on fruit development of loquat. Plant Growth Regulation, v.41, p.129-132, 2003.

AGUSTÍ, M.; JUAN, M.; ALMELA, V.; GARIGLIO, N. Loquat fruit size is increased through the thinning effect of naphthaleneacetic acid. Plant Growth Regulation, v.31, p.167-171, 2000.

BARBOSA, W.; POMMER, C.V.; RIBEIRO, M.D.; VEIGA, R.F.A.; COSTA, A.A. Distribuição geográfica e diversidade varietal de frutíferas e nozes de clima temperado no Estado de São Paulo. Revista Brasileira de Fruticultura, v.25, p.341-344, 2003.

CAMPO DALL'ORTO, F.A.; OJIMA, M.; BARBOSA, W.; SANTOS, R.R.; MARTINS, F.P.; SABINO, J.C. Nespereiras enxertadas em marmeleiro: nova opção de produção frutífera sob elevado adensamento de plantio. O Agronômico, v.42, p.17-27, 1990.
EMBRAPA. Centro Nacional de Pesquisa de Solos. Sistema Brasileiro de Classificação de Solos. Brasília: Embrapa-SPI; Rio de Janeiro: Embrapa-CNPS, 1999. 412p.

GONÇALVES, C.A.A.; LOPES, P.S.N.; ALVARENGA, A.A.; ABRAHÃO, E.; SOUZA, M. Enxertia de cinco cultivares de nespereira sobre o marmeleiro cv. Andramig I. Revista Brasileira de Fruticultura, v.18, p.437-440, 1996.

HAMADA, A.; YOSHIOKA, S.; TAKUMA, D.; YOKOTA, J.; CUI, T.; KUSUNOSE, M.; MIYAMURA, M.; KYOTANI, S.; NISHIOKA, Y. The Effect of Eriobotrya japonica seed extract on oxidative stress in Adriamycin-induced nephropathy in rats. Biology and Pharmaceutical Bulletin, v.27, p.1961-1964, 2004.

HARTMANN, H.T.; KESTER, D.E.; DAVIES JUNIOR, F.T.; GENEVE, R.L. Plant propagation: principles and practices. 7.ed. New Jersey: Prentice Hall, 2002. 880p.

ITO, H.; KOBAYASHI, E.; TAKAMATSU, Y.; LI, S.; HATANO, T.; SAKAGAMI, H.; KUSAMA, K.; SATOH, K.; SUGITA, D.; SHIMURA, S.; ITOH, Y.; YOSHIDA, T. Polyphenols from Eriobotrya japonica and their cytotoxicity against human oral tumor cell lines. Chemical and Pharmaceutical Bulletin, v.48, p.687693, 2000.

MARTÍNEZ-CALVO, J.; BADENES, M.L.; LLÁCER, G.; BLEIHOLDER, H.; HACK, H.; MEIER, U. Phenological growth stages of loquat tree (Eriobotrya japonica (Thunb) Lindl). Annals of Applied Biology, v.134, p.353-357, 1999.

MELO, A.A.M.; LIMA, L.C.O. Influência de três diferentes embalagens de PVC na vida pós-colheita de nêspera. Ciência e Agrotecnologia, v.27, p.1330-1339, 2003.

OJIMA, M.; CAMPO-DALL'ORTO, F.A.; BARBOSA, W.; MARTINS, F.P.; SANTOS, R.R. Cultura da nespereira. Campinas: Instituto Agronômico, 1999. 36p. (Boletim técnico, 185).

PIO, R.; CAMPO-DALL'ORTO, F.A.; BARBOSA, W.; OJIMA, M.; CHAGAS, E.A.; CIA, P. Produção de cultivares de nespereira na região Leste paulista. Pesquisa Agropecuária Brasileira, v.42, p.1053-1056, 2007a.

PIO, R.; CAMPO-DALL'ORTO, F.A.; CHAGAS, E.A.; BARBOSA, W. Aspectos técnicos do cultivo de nêsperas. Piracicaba: ESALQ/USP, 2007b. 28p. (Série Produtor Rural, 34).

SCALOPPI JÚNIOR, E.J.; JESUS, N.; MARTINS, A.B.G. Capacidade de enraizamento de variedades de nespereira submetidas à poda de renovação. Revista Brasileira de Fruticultura, v.26, p.61-64, 2004.

SILVA, J.A.A.; PEREIRA, F.M. Enraizamento de estacas herbáceas de nespereira (Eriobotrya japonica Lindl). Revista Brasileira de Fruticultura, v.26, p.369-371, 2004.

TANIGUCHI, S.; IMAYOSHI, Y.; KOBAYASHI, E.; TAKAMATSU, Y.; ITO, H.; HATANO, T.; SAKAGAMI, H.; TOKUDA, H.; NISHINO, H.; SUGITA, D.; SHIMURA, S.; YOSHIDA, T. Production of bioactive triterpenes by Eriobotrya japonica calli. Phytochemistry, v.59, p.315-323, 2002. 